\title{
Behaviorismo Radical e Discurso Pós-Moderno
}

\author{
José Antônio Damásio Abib ${ }^{1}$ \\ Universidade Federal de São Carlos
}

\begin{abstract}
RESUMO - Argumenta-se neste ensaio que o behaviorismo radical não apoia nenhum destes pressupostos do discurso moderno: fundacionismo na epistemologia, representacionismo na linguagem e as metanarrativas do progresso do Ocidente. Argumenta-se ainda que o behaviorismo radical é solidário com estas tendências do discurso pós-moderno: pragmatismo epistemológico, anti-representacionismo na linguagem e dissolução das metanarrativas do progresso científico, social, político e cultural do Ocidente. Sugere-se, finalmente, que o pensamento de Skinner rompe decisivamente com o discurso moderno e aproxima-se do discurso pós-moderno.
\end{abstract}

Palavras-chave: behaviorismo radical; discursos moderno e pós-moderno; behaviorismo epistemológico; epistemologia; hermenêutica.

\section{Radical Behaviorism and Post-Modern Discourse}

\begin{abstract}
In this essay it is argued that radical behaviorism does not support any of the following tenets of modern discourse: foundationism in epistemology, representationism in language and metanarratives of Western progress. It is argued that radical behaviorism is linked to the following tendencies of post-modern discourse: epistemological pragmatism, antirepresentacionism in language and the dissolution of the metanarratives of scientific, social, cultural and political progress of the West. Finally, it is suggested that Skinner's thought constitutes a decisive break with modern discourse in psychology, and is allied to post-modern discourse.
\end{abstract}

Key words: radical behaviorism; modern and post-modern discourses; epistemological behaviorism; epistemology; hermeneutics.

É como crítica não só ao representacionismo na epistemologia e na filosofia da linguagem, mas também a metanarrativas modernas, referentes ao progresso científico, político, social e cultural do Ocidente, que o discurso pós-moderno e a cultura pós-filosófica apresentam-se como possibilidades seja de desconstruir o discurso moderno, seja de diminuir sua importância no cenário intelectual contemporâneo (Lyotard, 1984, 1986/1989; Murphy, 1990; Rorty, 1980, 1985).

O behaviorismo radical apresenta notáveis analogias com essa crítica, porque, como defesa do anti-representacionismo na epistemologia e na linguagem (Abib, 1994a; Skinner, 1957, 1974) e também como crítica às metanarrativas do progresso do Ocidente (Skinner, 1953; 1986; 1990), ele já anunciava na psicologia os temas candentes desse discurso e dessa cultura; e com a ascensão recente dessa cultura e desse discurso é inegável o estímulo para revisitá-lo e destacar sua importância. Porque, de um lado, essa crítica alcançou a psicologia e, de outro lado, as propostas de psicologia pós-moderna e pós-filosófica são altamente programáticas (Chaiklin, 1992; Gergen, 1992; Kvale, 1992; Michael, 1992; Polkinghorne, 1992; Richer, 1992; Shotter, 1992; Young, 1992). Pelas semelhanças que apresenta com os temas do discurso pós-moderno, o behaviorismo radical tem condições de com ele dialogar produtivamente e pode apresentarse como alternativa menos programática para traçar diretrizes de uma psicologia pós-moderna e pós-filosófica.

1 Endereço: Universidade Federal de São Carlos, Departamento de Filosofia e Metodologia das Ciências, Via Washington Luiz, Km. 235. CEP: 13565-905 São Carlos - SP. Pesquisador do CNPq.
Apesar das críticas a que os conceitos de pós-modernidade, pós-modernismo e discurso pós-moderno vêm sendo submetidos (Chaiklin, 1992; Habermas, 1981; Jameson, 1984; Madsen, 1992), a defesa do anti-representacionismo na epistemologia já encontrava seu lugar não só no pragmatismo filosófico norte-americano, com a refutação feita por Dewey da teoria contemplativa do conhecimento, (Rorty, 1990/1993); mas também na filosofia da linguagem, com a dissolução que Wittgenstein (1953/1988) fez de sua própria teoria pictórica (picture theory) da linguagem - uma tendência na filosofia da linguagem que, mais recentemente, encontra sua expressão no neopragmatismo, com Davidson (Rorty, 1990/1993).

O discurso pós-moderno resgata e organiza esses temas, bem como reconhece os locais de suas inserções originais. E independentemente do destino desse discurso, os locais de onde retira inspiração para suas reflexões são suficientemente relevantes para orientar ponderações sobre a psicologia, especialmente no caso da psicologia do comportamento fundamentada no behaviorismo radical - uma filosofia da ciência e da mente solidária com o pragmatismo filosófico (Zuriff, 1985).

Com o objetivo de mostrar as relações entre o discurso pós-moderno e o behaviorismo radical, abre-se esse texto com uma breve apresentação da crítica pós-moderna não só ao representacionismo na epistemologica e na filosofia da linguagem, mas também às metanarrativas do discurso moderno. A seguir os temas do discurso pós-moderno são retomados no behaviorismo radical com o propósito de fundamentar a alegação dos notáveis parentescos entre esses dois estilos de discurso. 


\section{Discursos Moderno e Pós-Moderno}

Da perspectiva filosófica, o discurso moderno pode ser descrito como defesa do fundacionismo na epistemologia e do representacionismo na filosofia da linguagem, e o discurso pós-moderno como defesa do holismo na epistemologia e da teoria do significado como uso na filosofia da linguagem (Murphy, 1990). Para se referir a essa virada (turn) no pensamento filosófico, Rorty (1980) recorre aos conceitos de cultura filosófica e pós-filosófica, onde o primeiro significa fundacionismo na epistemologia e filosofia "impura" da linguagem, e o segundo, behaviorismo epistemológico e filosofia "pura" da linguagem.

Fundacionismo na epistemologia significa que o conhecimento representa a realidade, no sentido de que a mente constrói representações do mundo externo. Desse ponto de vista, argumenta-se que os seres humanos têm acesso privilegiado à mente e por isso são capazes de compreender como ela funciona na elaboração de idéias indubitáveis e verdadeiras sobre a realidade - idéias que representam o que existe fora delas bem ali no mundo externo. A filosofia "impura" da linguagem é uma versão mais recente do fundacionismo epistemológico, no sentido de que se o trabalho representacional da mente não for capaz de justificar o conhecimento certo e verdadeiro, as palavras podem fazê-lo de acordo com a teoria referencial do significado.

A filosofia "pura" da linguagem não tem qualquer compromisso com essa nova versão do fundacionismo na epistemologia, o que significa dizer que a teoria referencial do significado é substituída pela teoria do significado como uso no sentido de Wittgenstein (1953/1988). De acordo com Wittgenstein, "a palavra 'significado' é usada ilicitamente se o for para significar a coisa que 'corresponde' à palavra" (§ 40). E mais, não há nada na mente que possa constituir significados, porque os significados de palavras relacionamse com o seu uso na linguagem (Wittgenstein, 1953/1988, 1958/1989). Segundo Hanfling (1989), o conceito de linguagem de Wittgenstein não se refere a uma realidade subjacente que seja independente de práticas e necessidades humanas. Wittgenstein (1953/1988) entende que linguagem significa diversidade de linguagens ou jogos de linguagem, que se constituem como "novos tipos de linguagem, novos jogos de linguagem" ( $\$ 23)$. O conceito de jogo de linguagem destaca o ato de falar uma linguagem como parte de uma forma de vida ou de uma atividade. Existem muitos tipos de jogos de linguagem, como descrever um objeto, dar ordens, perguntar, construir uma história, fazer uma piada, saudar, orar, etc. Significado como uso em jogos de linguagem refere-se a contextos, ambientes, situações, atividades e formas de vida. Na teoria dos atos de fala, tem-se procurado esclarecer os vários sentidos de significado como uso em jogos de linguagem (Austin, 1962/1975; Searle, 1969/1989). O conceito de linguagem como uso está hoje disseminado na filosofia da linguagem (Lyotard, 1984; Murphy, 1990; Rorty, 1980, 1990)

O behaviorismo epistemológico é um holismo, porque a justificação do conhecimento remonta à conversação e prá- tica social, sem remeter a qualquer relação especial entre idéias, palavras e coisas (Rorty, 1980). Trata-se de um holismo-com-pragmatismo (holism-cum-pragmatism) (Murphy, 1990), uma vez que se articula com a teoria pragmática da verdade para justificar o conhecimento. Isso quer dizer que a verdade e a justificação do conhecimento relacionam-se com os participantes de uma prática social e, sendo assim, abandona-se o projeto de reivindicar certeza ou conhecimento absoluto com base na verdade compreendida como correspondência entre idéias, palavras e coisas (Rorty, 1980).

O discurso moderno envolveu-se completamente com a crença de que todas as ciências trariam progresso para o gênero humano (Lyotard, 1984, 1986/1989), ao mesmo tempo em que teriam seus discursos legitimados por um metadiscurso ou um discurso filosófico. Os resultados foram as metanarrativas, como as seguintes: as ciências serão capazes de descobrir como as coisas são realmente, o progresso científico, político, social e cultural do Ocidente promoverá a emancipação do sujeito racional bem como criará abundância. No entanto, Lyotard (1984) escreve que "após dois séculos estamos mais sensíveis a sinais que significam o contrário" (p. 6).

Rorty (1985) comenta que Lyotard (1984) "define pósmoderno como incredulidade em metanarrativas" (p. 161) e faz um apelo: "Poderíamos concordar com Lyotard que não temos mais necessidade de metanarrativas" (p. 173). Contudo, Rorty não está inteiramente de acordo com Lyotard sobre o significado de epistemologia no discurso pós-moderno. Ele critica o conceito de paralogia de Lyotard, a idéia de que a ciência está em revolução permanente. Argumenta contra Lyotard que a ciência consiste em um revezamento entre normalidade e revolução no sentido de Kuhn (1962). De acordo com Kuhn, a ciência normal é guiada por um paradigma que define, por um certo tempo, um conjunto de regras para encaminhar e solucionar seus problemas, produzindo realizações científicas reconhecidas universalmente pela comunidade de cientistas dedicados a ela. Quando o paradigma da ciência normal torna-se inoperante na solução de seus problemas e atinge o nível de uma crise profunda, surge a ciência revolucionária com propostas de paradigmas rivais.

Rorty (1980) generaliza as distinções de Kuhn para todos os tipos de discursos: "O behaviorismo epistemológico distinguira entre discursos comensuráveis [discursos redutíveis um ao outro] e incomensuráveis [discursos irredutíveis um ao outro] como discursos "normais" e "anormais"" (p. 320). Com base nessa tipologia de discursos, Rorty define epistemologia como uma atitude que pode ser assumida para discursos "normais", ou para uma conversação em que existe um conjunto de regras que orientam os participantes na obtenção de acordos racionais; e define hermenêutica como outra atitude, que pode ser tomada diante de discursos "anormais", ou perante uma conversação onde os participantes não são capazes de dirimir desavenças exatamente porque não existe um conjunto de regras para orientar acordos racionais.

O esboço de Murphy (1990) concernente aos discursos moderno e pós-moderno adquire contornos mais precisos e 
contribui para melhor diferenciá-los se o discurso moderno significar não só fundacionismo na epistemologia e representacionismo na filosofia da linguagem, mas também credulidade em metanatrativas; e se o discurso pós-moderno significar não só holismo na epistemologia e teoria do significado como uso na filosofia da linguagem, mas também incredulidade em metanarrativas. Finalmente, se holismo na epistemologia é interpretado como behaviorismo epistemológico, então são diferentes os conceitos de cultura pós-filosófica de Rorty (1980) e de discurso pós-moderno de Lyotard (1984).

\section{Behaviorismo Radical e Epistemologia}

O behaviorismo radical é filosofia da ciência do comportamento - não é ciência do comportamento (Skinner, 1974). No entanto, há uma interdependência entre o behaviorismo radical e a ciência do comportamento, porque se, por um lado, delineia-se no primeiro uma concepção de comportamento (o comportamento operante), por outro lado, o desenvolvimento da segunda permite a Skinner aprofundar sua filosofia da ciência do comportamento. Apoiado então nessa filosofia e ciência, o filósofo, cientista e psicólogo norteamericano realiza interpretações originalíssimas de fenômenos mentais, políticos, sociais, morais e culturais (Skinner, 1953, 1971, 1974, 1986).

Skinner (1957) interpreta o conhecimento científico como sendo predominantemente o comportamento verbal de cientistas, sendo, portanto, passível de ser investigado pelo behaviorismo radical - o que significa dizer, em última análise, que o behaviorismo radical não é apenas filosofia da ciência do comportamento, mas também filosofia ou epistemologia da ciência (Zuriff, 1985). Mas não se trata de fundacionismo epistemológico, porque o antimentalismo e o anticognitivismo de Skinner (1953, 1977), bem como sua crítica à teoria referencial do significado (Abib, 1994a; Skinner, 1957) e ainda sua defesa de uma epistemologia interativa-pragmática (Burton, 1980; Skinner, 1956/1972,1957, 1974; Zuriff, 1985) significam que sua teoria do conhecimento é intratável da perspectiva do fundacionismo epistemológico.

\section{Behaviorismo Radical e Epistemologia Interativa- Pragmática}

Skinner (1974) fez três comentários sobre a natureza da ciência. Ele disse, em primeiro lugar, que ciência é comportamento verbal de cientistas regido por um corpo de regras para o desempenho de ações efetivas. Segundo, que, embora essas regras descrevam contingências, elas jamais são as próprias contingências, e isso porque "o comportamento evocado por uma regra é frequientemente mais simples do que o comportamento modelado pelas contingências, das quais as regras são derivadas" (Skinner, 1969, p. 167). Terceiro, que a verdade de uma regra ou proposição depende de sua capacidade de ajudar ouvintes a agir apropriadamente às situações que elas descrevem. De acordo com Zuriff
(1985), o behaviorismo radical é nesse sentido "uma epistemologia empírica, ou uma teoria do conhecimento derivada de uma investigação científica da psicologia do conhecedor" (p. 251). Do ponto de vista epistemológico de Skinner, o comportamento do cientista interage com dois universos, o de sua própria experiência e o da comunidade científica. $\mathrm{Ou}$ ainda, o comportamento do cientista interage com as contingências de sua própria experiência e com as regras da comunidade científica.

Segundo Skinner (1957), aprende-se comportamento científico de acordo com as contingências de reforçamento estabelecidas por uma comunidade científica. Basicamente, essa comunidade ensina o aprendiz a comportar-se de acordo com regras, cujo objetivo é não só instruí-lo para a tarefa de realizar descrições e relatos precisos de seus experimentos, mas também educá-lo para o debate científico e comunicações com seus pares, contribuindo assim para o desenvolvimento da ciência. Contudo, um corpo de regras, científicas ou não, contém imprecisões, porque uma regra é um plano formulado com base na análise de contingências, e se o resultado dessa análise for deficiente, ela pode conter equívocos, ambigüidades, etc. (Skinner, 1969, 1986). No caso da ciência, é a própria experiência científica do cientista que pode contradizê-las; e se sua competência for comprovada, é o valor de verdade das regras que é posto em dúvida, correndo o risco de eventualmente serem falsificadas.

A face interativa da epistemologia do behaviorismo radical legitima o conceito de ambiente aberto do cientista. Na verdade, desde os anos cinqüenta, Skinner (1956/1972) já alargava a noção de ambiente do cientista com o conceito de serendipidade \{serendipity): o conjunto de acidentes que podem ocorrer durante a realização de uma pesquisa. Por exemplo, ele narra um detalhado estudo de caso de sua própria pesquisa experimental para mostrar como acidentes que ocorreram no transcurso da pesquisa contribuíram para sua concepção e desenvolvimento da abordagem experimental do método de estudo de caso. Engenhosamente, conclui que o método experimental de caso-único (single-case) é mais adequado para estudar fenômenos de aprendizagem do que o método científico de delineamento estatístico com grupos experimental e de controle e o método dedutivo. E nesse sentido, "é um erro identificar a prática científica com as construções formalizadas da estatística e do método científico. Essas disciplinas (...) oferecem um método de ciência, mas não, como se supõe tão freqüentemente, o método" (Skinner, p. 101).

Burton (1980) sugere que, no uso de Skinner, o ambiente do cientista é suficientemente aberto para incluir não somente os procedimentos canonizados do método cientifico, mas também "influências econômicas, sociais e políticas' (p. 117), concluindo com esse alargamento que a epistemologia interativa-pragmática do behaviorismo radical desponte seguramente como prática social - uma conclusão defendida também por Zuriff (1985).

A face pragmática da epistemologia do behaviorismo radical, cujos aspectos serão gradativamente apresentados no decorrer desse texto, afasta Skinner do debate aparên- 
cia-essência ou aparência-realidade, uma das principais controvérsias entre positivistas e realistas (Kolakowski, 1966/ 1976; Zuriff, 1985). Segundo Zuriff, realidade para Skinner não se refere à existência de entidades subjacentes (imutáveis, eternas, independentes do tempo ou do espaço) nem aparência remete para o que é mutável, perecível, histórico e temporalmente situado; para Skinner, realidade-aparência significa comportamento efetivo-inefetivo. Está-se diante de uma perspectiva pragmática similar à do humanismo pragmático de James (1907/1988), no sentido de que "o mundo permanece realmente maleável, esperando receber seu toque final de nossas mãos (...). O homem engendra verdades sobre o mundo" (p. 115). Na linguagem de Skinner (1969) isso significa dizer que as leis científicas, por exemplo,"não são (...) obedecidas pela natureza, mas por homens que tratam efetivamente com a natureza" (p. 141). Referindo-se mais especificamente à lei da queda dos corpos, Skinner afirma que ela "não governa o comportamento da queda dos corpos; ela governa aqueles que predizem corretamente a posição da queda dos corpos em certos momentos" (p. 141).

As faces interativa e pragmática do behaviorismo radical conduziram Burton (1980) a propor que Skinner, como todos os pragmatistas, concebe a ciência na perspectiva do relativismo, porque para ele a ciência não reivindica princípios e conhecimentos absolutos. Por isso, Burton situa a epistemologia de Skinner nas tendências recentes da filosofia e história da ciência pós-empirista, que conta com expoentes como Kuhn, Lakatos e Feyerabend (Bernstein, 1989). Por um lado, essa última conclusão de Burton faz sentido do ponto de vista da epistemologia interativa-pragmática de Skinner, mas, por outro lado, gera dúvidas, porque usualmente o behaviorismo radical é associado não somente com o positivismo, mas também com a história linear-empirista da ciência (Zuriff, 1985). Contudo, há muitos equívocos com relação à posição de Skinner sobre essas questões. Com o objetivo de apontá-los e esclarecê-los, serão apresentadas características do pensamento positivista e da história linear-empirista da ciência, bem como os afastamentos de Skinner com respeito a essas tendências de pensamento.

\section{Behaviorismo Radical e Positivismo}

Kolakowski (1966/1976) apresenta uma análise iluminadora da tradição de pensamento positivista, onde destaca quatro características básicas desse pensamento. Para começar, não há para positivistas qualquer sentido na pesquisa de essências (o debate aparência-essência), nem na investigação sobre a natureza última da realidade (o debate nominalismo-realismo). E mais, para eles, o método científico é universal para as ciências da natureza e do homem, bem como defendem uma distinção irredutível entre fatos e valores, no sentido de que não é logicamente possível derivar proposições referentes a valores a partir de proposições concernentes a fatos, ou seja, as primeiras não têm estatuto cognitivo.

A epistemologia interativa-pragmática do behaviorimo radical representa um afastamento notável dessas caracteristicas do positivismo. Em primeiro lugar, a posição pragmáti- ca de Skinner (1957) no debate aparência-essência, como comportamento inefetivo-efetivo, permite-lhe distanciar-se dos termos tradicionais desse debate, isentando-o de qualquer pronunciamento seja a favor do eventual estatuto cognitivo das aparências, seja contra a pesquisa nonsense das essências. Segundo, não há, para Skinner, método científico universal, o que significa dizer que as práticas científicas não devem ser, necessariamente, identificadas com os aspectos formais do método científico e do raciocínio dedutivo. Além disso, coloca que essas práticas não devem também ser identificadas com as feições reducionistas desse método - método científico que, na ciência do comportamento, procura explicar os fenômenos comportamentais e suas leis reduzindo-os a fenômenos e leis fisiológicas, mentalistase cognitivas (Johnson, 1963; Skinner, 1950,1956/ 1972). Nem tampouco, finalmente, devem as práticas científicas na ciência do comportamento seguir a orientação do método científico que estabelece limites metodológicos para a investigação de eventos privados, abandonando-se, desse modo, a investigação de eventos como sentimentos, desejos, intenções, etc. (Skinner, 1945, 1974).

Terceiro, Skinner (1971) rejeita a distinção positivista entre fato e valor, atribuindo estatuto cognitivo aos juízos de valor (Garret, 1979; Graham, 1977; Rottschaefer, 1980; Waller, 1982). Sendo assim, argumenta a favor de uma teoria cognitiva dos valores éticos, diferente, portanto, da teoria emotivista desses valores defendida por pensadores positivistas como Ayer (1936/1971) e Stevenson (1959/1965) - uma teoria onde, precisamente, eles não têm estatuto cognitivo. Quarto, no debate nominalismo-realismo, Skinner (1974) não se compromete com qualquer tipo de realismo, seja com idéias e eventos cognitivos da mente, seja com motivos, emoções e pulsões da psique. Naturalmente, isso não significa que ele esteja negando a existência da percepção, do pensamento, dos sentimentos, motivos, emoções, pulsões, etc. O que está sendo negado é que esses eventos sejam dotados de uma substância mental especial, em um sentido similar àquele em que Ryle (1949/1980) rejeitou a existência do fantasma na máquina e James (1912/1976) recusou a concepção substancialista da consciência. O que está implícito na epistemologia do behaviorismo radical é uma teoria relacionai ou funcional de mente (Zuriff, 1985). Nesse sentido, a crítica de Skinner (1953, 1957) às hipóstases e reificações de conceitos e abstrações mentais, bem como suas objeções à teoria referencial do significado representam posições opostas ao realismo filosófico. Em última análise, isso significa dizer que não é possível formular descrições, científicas ou não, com condições de se referir ou corresponder ao mundo, uma vez que não há entidades transcendentes existentes no mundo suscetíveis de serem representadas por idéias ou palavras independentemente dos seres humanos.

Ao posicionar-se contra o realismo no debate nominalismo-realismo, Skinner compartilha com pensadores positivistas uma crença no nominalismo; no fundo, uma crença assimilada também pelo pragmatismo: "Ele [o pragmatismo] concorda com o nominalismo, por exemplo, apelando 
sempre para particulares" (James, 1907/1988, p. 29). Ou seja, como redige Zuriff (1985): "Isso [nominalismo] significa que abstrações [conceitos, idéias] (...) são relacionadas ao concreto e particular bem como às relações entre elas" (p. 269).

\section{Behaviorismo Radical e Empirismo}

A história linear-empirista da ciência associa-se com pelo menos três suposições do empirismo. A primeira é a de que existe observação pura dos fenômenos e eventos sob investigação - uma observação processada independentemente de pressuposições teóricas que constituem os "dados brutos" da ciência. A segunda é a de que há uma relação direta entre os dados dessa observação e as teorias científicas, sendo com base neles e a partir deles que essas teorias desenvolvem-se. Finalmente, são essas teorias que predizem quais são os próximos dados a serem descobertos com a investigação experimental, sendo confirmadas ou refutadas caso as evidências experimentais apoiem ou não suas previsões - e se uma teoria for refutada nessa base, deverá ser corrigida por uma mais abrangente. Consagrada por essas suposições, a história empirista da ciência desenrola-se, persistentemente, no propósito de demonstrar o progresso cumulativo, linear e contínuo da ciência. À filosofia e história da ciência pós-empirista representam concepções diferentes da ciência e de sua evolução. Os filósofos e historiadores da ciência solidários com essa tendência defendem que não há observação pura nem "dados brutos", porque ela é carregada de pressuposições teóricas e, conseqüentemente, não há também uma distinção nítida entre dados e teorias. E mais, o progresso da ciência é necessariamente descontínuo e incomensurável, porque as revoluções científicas processam-se de acordo com o conceito de paradigma de Kuhn (1962) onde não se admite a redutibilidade de um paradigma científico a outro.

Com referência a esse debate, pode-se fazer pelo menos três observações que contribuem para distanciar a epistemologia interativa-pragmática do behaviorismo radical da história linear-empirista da ciência. No behaviorismo radical, os relatos observacionais remetem à linguagem de dados comportamentais (Zuriff, 1985). Isso quer dizer que relatos observacionais remetem, obviamente, a uma base observacional. Essa base é, por sua vez, invadida por categorias comportamentais (por exemplo, contingências de reforço e métodos para coligir dados). Sendo assim, observações dependem de uma concepção prévia do comportamento, que as modifica em relatos observacionais "contaminados" pela linguagem de dados comportamentais. E mais, a crítica de Skinner (1950, 1974) às teorias fisiológicas, mentalistas e cognitivas [uma posição muito similar à de Wittgenstein (1953/1988), quando escreve que "explicações terminam em algum lugar" (§ 1), no sentido em que Skinner $(1950,1974)$ identifica explicações com descrições no nível do comportamento; bem como uma crítica fundamental à idade da teoria, uma das características marcantes do estilo de discurso moderno (Kvale \& Grenness, 1967; Kvale, 1992)] não o compromete com os "dados brutos" da observação pura, nem com observações onde a linguagem esteja neutralizada, porque, de qualquer modo, suas categorias comportamentais impregnam as observações que são feitas com um tipo de linguagem comportamental (Abib, 1997).

Finalmente, Hoccut (1985) comenta que, em sua maior parte, o empirismo no behaviorismo, e no behaviorismo radical como uma de suas versões foi muito mais programático do que uma prática efetiva de pesquisa, porque o pragmatismo é, na verdade, a filosofia mais relevante para legitimar as práticas de pesquisa do behaviorismo. Isso significa dizer que na "perspectiva do pragmatismo, não existe tal coisa como um dado puro, não-interpretado" (Hoccut, p. 81). Para diferenciar dados de teorias, em vez da teoria da correspondência, Hoccut recorre à teoria pragmática da verdade, defendendo, portanto, no lugar do acordo entre proposições efatos do mundo externo, o acordo entre descrições de cientistas: "Consideramos como dados declarações sobre as quais não se constatam mais sérias disputas, e como teorias aquelas que permanecem sujeitas a sérias dúvidas entre os membros informados e competentes da comunidade científica" (p. 80). Skinner (1974) afirmou que o "behaviorismo metodológico e algumas versões do positivismo lógico colocaram os eventos privados fora dos limites [da ciência do comportamento] porque não poderia haver acordo público sobre sua validade (...). [O behaviorismo radical] não insiste na verdade por acordo e pode, por isso, considerar os eventos que ocorrem no mundo privado dentro da pele. Ele não os chama de inobserváveis nem os nega como subjetivos" (P- 16).

Agora, parece haver uma contradição entre esse enunciado e a epistemologia interativa-pragmática de Skinner. Mas a contradição é apenas aparente, porque, sem que seja possível examinar mais detalhadamente, aqui, as implicações dessa declaração, a noção de verdade por acordo no pragmatismo bem como no positivismo lógico e no behaviorismo metodológico não significa a mesma coisa. Com efeito, o pragmatismo é uma filosofia diferente do empirismo (Murphy 1990/1993; Wiley, 1994/1996), e ao menos em suas versões iniciais, o positivismo lógico esteve comprometido com o empirismo (Ayer, 1959/1965). Além disso, Skinner (1945, 1974) está apenas fazendo uma objeção, vigorosa sem dúvida, aos defensores do behaviorismo metodológico, que admitiam a existência dos fenômenos subjetivos, não os incluindo, entretanto, no âmbito da ciência, por não serem publicamente observáveis. Na verdade, Skinner estava propondo um programa filosófico e científico diferente daquele do positivismo lógico e do behaviorismo metodológico com o propósito de examinar os "eventos subjetivos" para elaborar uma filosofia da mente. Em suma, a epistemologia do behaviorismo radical é mais solidária com o pragmatismo do que com o positivismo e o empirismo.

\section{Behaviorismo Radical, Objetivismo e Relativismo}

Como foi visto, Burton (1980) sugeriu que precisamente por causa de sua face pragmática, a epistemologia de Skinner insere-se no relativismo, longe, portanto, do objetivismo epis- 
temológico. Do ponto de vista do objetivismo epistemológico, a meta da ciência é descobrir o conhecimento verdadeiro. Isso que é exatamente negado no relativismo, porque, segundo essa tendência de pensamento, o conhecimento é produzido em contextos históricos, sociais e culturais específicos, bem como depende de esquemas conceituais e de estruturas teóricas legitimadas por esses contextos. O relativismo é, portanto, um ceticismo quanto à possibilidade da ciência instituir um conhecimento capaz de transcender não só contextos históricos, sociais e antropológicos nos quais é produzido, mas também os esquemas conceituais e as estruturas teóricas legitimados por essas inserções. No debate travado agora por relativistas e objetivistas, esses acusam aqueles, desde Platão, de serem "auto-referencialmente inconsistentes e paradoxais" (Bernstein, 1989, p. 9). Ou seja, como (reconheçam ou não) os relativistas defendem que sua posição é verdadeira ao mesmo tempo que afirmam que a verdade é relativa, o paradoxo e a inconsistência estão instalados, podendo-se, conseqüentemente, admitir como verdadeiro algo que também pode ser falso. E mais, o "relativismo pode ser ele mesmo verdadeiro $e$ falso. Não se pode defender o relativismo sem arruiná-lo" (Bernstein, p. 9).

Como foi sugerido por Burton (1980), nesse debate a epistemologia de Skinner realmente não se alinha com o objetivismo epistemológico; mas, contra esse autor, defende-se, aqui, que tampouco a epistemologia interativa-pragmática do behaviorismo radical descamba para o relativismo. Isso porque, precisamente, seu lado pragmático afasta-a dessa tendência de pensamento - o mesmo aspecto, portanto, ressaltado por Burton para aproximá-la do relativismo. No pragmatismo, a reivindicação de conhecimento verdadeiro deve apresentar como evidência seu funcionamento e efetividade, ou seja, se um determinado conhecimento funciona e é, portanto, efetivo, seu valor de verdade está assegurado; caso contrário, não. Como defendeu James, verdade em nossas idéias significa seu poder de funcionar (1907/1988). Na linguagem de Skinner, isso significa que "uma parte importante da prática científica é a avaliação de que uma resposta verbal seja "correta" ou "verdadeira", ou de que possa funcionar afortunadamente" (1957, p. 428).

O behaviorismo radical enfatiza, como valores importantes de uma ciência do comportamento, a pesquisa de leis, predição e controle do comportamento (Zuriff, 1985). O valor de verdade ou a efetividade do conhecimento produzido por essa ciência depende de se ela promove ou não esses valores. Em um exame crítico da efetividade dessa ciência em promover seus objetivos, Lacey e Schwartz (1986) argumentam que ela é adequada para tratar com situações fechadas, como as fábricas do sistema capitalista, sendo, no entanto, inadequada para tratar com situações mais abertas e imprevisíveis, como as interações cotidianas. Se a epistemologia do behaviorismo radical situa-se na perspectiva do relativismo, como quer Burton (1980), e se a crítica de Lacey e Schwartz for válida (será argumentado que não é), então o paradoxo e a inconsistência estão instaladas nessa epistemologia, porque ela estaria orientando a produção de um conhecimento que pode ser visto como verdadeiro em uma situação e falso em outra. No entanto, é um equívoco pensar dessa maneira, porque, da perspectiva pragmática dessa epistemologia, podese argumentar que não é seu objetivo orientar a produção de conhecimento para situações abertas e imprevisíveis, e que já seria um avanço se a ciência do comportamento pudesse contribuir para compreender como se processam as relações de trabalho nas situações fechadas das instituições capitalistas. Por exemplo, usando esse conhecimento, os trabalhadores poderiam tentar contracontrolar o controle que é exercido sobre eles por essas instituições. E também nesse sentido que, de uma perspectiva pragmática, seria errôneo pensar que uma teoria do comportamento seria tão boa quanto qualquer outra para tratar com situações fechadas. Ou seja, uma teoria do comportamento, cujo interesse dirige-se para a compreensão do controle do comportamento, provavelmente será mais efetiva para mostrar como o contracontrole pode ser implementado do que uma que não tenha esse objetivo.

$\mathrm{Na}$ verdade, Skinner $(1953,1986)$ nunca limitou o behaviorismo radical ao exame de situações fechadas, tendo também estendido suas análises para a predição e controle do comportamento em situações mais abertas e imprevisíveis. Isso significa dizer que a crítica de Lacey e Schwartz erra o alvo, seja porque não leva em conta as análises mais amplas de Skinner, seja porque não percebem que o comportamento operante carrega consigo um mínimo de incerteza. Sendo este mínimo de incerteza bem expresso por Skinner, quando frequientemente afirma que o operante tem somente uma probabilidade de ocorrência, ou que, embora o "comportamento seja regido por leis, (...) não temos a informação necessária para predizer com certeza o momento de sua ocorrência" (1968, p. 138). Esse aspecto do operante levou Baldwin (1988) a apontar similaridades básicas nos pensamentos de Skinner e Mead, com respeito ao conceito de agente do comportamento - um conceito que poderia ser considerado na análise de situações mais abertas e imprevisíveis (Baldwin, 1988; Skinner, 1957, 1968, 1974; Zuriff, 1985). Isso quer dizer que, embora o comportamento seja regido por leis, um enfraquecimento das noções de predição e controle e a introdução da perspectiva do agente poderiam constituir-se como estratégia mais promissora para tratar com situações abertas e imprevisíveis. É nesse sentido que Zuriff escreve: "Talvez as injunções correntes dos behavioristas sobre a ciência não maximizem de fato predição e controle, [ou] talvez predição e controle não sejam os reforçadores mais poderosos que controlam o comportamento do cientista" (p. 278).

Cabe, agora, um breve desvio na direção do discurso pósmoderno, porque, nesse caso, a objeção à epistemologia objetivista é ainda mais radical (Bernstein, 1989; Lather, 1992; Murphy, 1990; Polkinghorne, 1989). Polkinghorne comenta que o objetivismo e o relativismo são orientados pela idéia do conhecimento de uma realidade em si - um crédulo e o outro cético. Lather escreve que "relativismo é um conceito de outro discurso, um discurso de fundamentos" (p. 99). Murphy observa que o discurso pós-moderno consiste no abandono radical de dicotomias do tipo objetivismo-relativismo. Bernstein argumenta que é necessário ultrapassar a dicotomia objetivismo-relativismo, o que significa negá- 
los como tarefa teórica e assumi-los como prática (praxis). Ou seja, de acordo com esses autores, o discurso pós-moderno não representa uma defesa do relativismo contra o objetivismo, porque essa dicotomia não somente representa um pseudoproblema, mas também pertence ao estilo do discurso moderno.

Em suma, a epistemologia interativa-pragmática do behaviorismo radical não é solidária nem com o objetivismo nem com o relativismo, porque o pragmatismo não é nem uma coisa, nem outra (James, 1907/1988; Rorty, 1982). Além disso, conjurar o fantasma do relativismo quando uma posição epistemológica é conjeturada longe do objetivismo epistemológico e próxima do pragmatismo é não perceber que o pragmatismo filosófico pode ser uma alternativa para essa falsa dicotomia (James, 1907/1988; Rorty, 1982) bem como é permanecer aprisionado nas armadilhas do discurso moderno (Bernstein, 1989; Lather, 1992; Murphy, 1990; Polkinghorne, 1989).

\section{Behaviorismo Radical, Linguagem e Comportamento Verbal}

As concepções de Skinner sobre linguagem e comportamento verbal são anti-representacionistas porque, de um lado, ele não aceita a teoria tradicional do significado e, de outro lado, porque elabora uma teoria funcional do significado que não implica o conceito de referência (Abib, 1994a; Skinner, 1957). A teoria tradicional do significado apresenta-se em duas versões, como teoria da expressão de idéias e como teoria referencial do significado (Lyons, 1977/1980; Skinner, 1957). Na teoria da expressão de idéias, palavras significam idéias diretamente e coisas indiretamente, através de seus próprios significados, isto é, as idéias (Lyons). Na teoria referencial do significado, palavras significam diretamente coisas, onde o significado das palavras não são mais as idéias, mas, sim, as próprias coisas, ou seus referentes (Lyons).

Ambas as versões da teoria tradicional do significado são invadidas pelo conceito de representação. Assim, na teoria da expressão de idéias, palavras representam idéias, que, por sua vez, representam coisas, porque, desde Descartes, idéia significa representação mental, imagem, conceito, objeto de pensamento, ou ainda uma representação da mente que conhece e percebe (Urmson, 1972). Já na teoria referencial do significado, as palavras representam diretamente coisas, sem intermediação de idéias.

São muitas as críticas que Skinner (1957) dirige a essas teorias - críticas que foram examinadas detalhadamente por Abib (1994a). Mais importantes do que revê-las aqui, já que, de modo geral, fundamentam-se no anti-representacionismo epistemológico de Skinner, é apresentar brevemente não só as concepções de Skinner sobre linguagem e comportamento verbal, mas também sua teoria funcional do significado.

Linguagem refere-se a práticas de reforçamento de comunidades verbais ou culturas, práticas que são governadas por regras gramaticais (Skinner, 1957, 1969, 1989). Como comunidades verbais são culturas constituídas por ouvintes, mais exatamente linguagem significa o comportamento de ouvintes governado por regras gramaticais, que estão registradas em gramáticas e que existem mesmo quando "ninguém as está falando" (Skinner, 1989, p. 87). Comportamento verbal refere-se ao comportamento de falantes individuais - comportamento que é adquirido de acordo com as práticas de reforçamento de comunidades verbais na medida em que essas práticas são governadas por regras gramaticais. Ou seja, o comportamento do falante é modelado e mantido pelo comportamento de ouvintes na medida em que esse é governado por uma linguagem: as regras gramaticais contidas em gramáticas.

Se o comportamento é modelado e mantido de acordo com as contingências verbais de uma cultura, ele se instala como uma relação indissociável entre uma situação, resposta e conseqüência, e é essa relação que significa algo, e tem significado (Abib, 1994a; Skinner, 1957, 1974). Em outras palavras: à medida que o comportamento verbal é adquirido como uma relação dessa natureza, a história de contingências verbais passa a constituí-la como significado. Por isso Skinner afirma que "o significado está em uma história (...) história de exposição às contingências" (1974, p. 90). É como relação que o significado do comportamento verbal está em uma história de contingências verbais e é também como relação que o comportamento verbal significa algo, pois é como relação entre uma situação atual e uma resposta verbal que essa resposta "significa uma outra relação que é a história de contingências de reforçamento - isto é, o significado - responsável pela instanciação daquela relação no presente" (Abib, 1994a, p. 486).

Seja pela epistemologia anti-representacionista que orienta suas concepções sobre linguagem e comportamento verbal, seja pelo vocabulário de sua teoria funcional do significado, o pensamento de Skinner é solidário com a "filosofia pura" da linguagem e rompe, conseqüentemente, com a filosofia "impura da linguagem", ou com as versões da teoria tradicional da linguagem - a teoria da expressão de idéias e a teoria referencial do significado.

A teoria funcional do significado não só não tem qualquer vínculo com a teoria da expressão de idéias - pelo simples fato de que o termo idéia já remete, como foi visto, à noção de representação mental - como também não implica o conceito de referência (Abib, 1994a; Skinner, 1957). Nesse caso, o argumento de Skinner relaciona-se com o contextualismo de sua análise da linguagem e do comportamento verbal (Abib). Sem que seja possível apresentar detalhadamente, aqui, esse argumento, cabe comentar que nenhum tipo de comportamento verbal - como os ecóico, textual, mando, tacto e intraverbal - representa coisas, objetos, eventos e suas propriedades (supostamente situados no mundo externo), porque os significados desses comportamentos não são independentes dos contextos da linguagem e da cultura. Ou seja, é das regras de uma linguagem e de uma cultura que o comportamento verbal adquire significado, mas "essas regras não descrevem e/ou governam o comportamento de coisas no mundo externo. Como, então, seria possível, à vista disso, o comportamento verbal referir-se a alguma coisa, objeto ou evento desse mundo?" (Abib, p. 485). 
Com a teoria funcional do significado, Skinner assesta mais um golpe na epistemologia do representacionismo. Resta ainda mostrar como o talentoso psicólogo norte-americano é também incrédulo com respeito a metanarrativas.

\section{Behaviorismo Radical e Metanarrativas}

O pensamento de Skinner não tem compromissos com qualquer tipo de metanarrativas. Sua epistemologia interativapragmática e seu distanciamento da história linear-empirista da ciência não significam nem uma promessa, nem uma crença em metanarrativas científicas. Ou seja, ele não defende que a ciência e a história da ciência, orientadas, respectivamente, pelo positivismo e empirismo, sejam capazes de descobrir como as coisas realmente são, para, a partir daí, indicar o sentido do progresso, ensinando os seres humanos a conquistá-lo, por meio de ações em consonância com uma realidade objetiva.

O pensamento político e social de Skinner (1953, 1986, 1990) apresenta importantes alternativas visando habilitar as pessoas a enfrentarem problemas sociais e políticos em seus ambientes com o objetivo final de torná-los mais habitáveis para si mesmas. No entanto, isso não significa que ele esteja defendendo metanarrativas políticas e sociais - narrativas vislumbrando a emancipação do sujeito racional e a criação de abundância, com base no progresso social, político e cultural do Ocidente. Skinner não acredita que as teses do iluminismo, com suas promessas não só de esclarecimento dos seres humanos pelos expertos da cultura, mas também de desenvolvimentos social e político no caminho da liberdade e justiça (Habermas, 1981) tenham sido realizadas. Na verdade, como Lyotard (1984), Skinner vê "sinais que significam o contrário".

Skinner (1986) criticou a sociedade capitalista dos países desenvolvidos. Primeiro, ele comenta o aspecto já bem conhecido das relações alienadas instauradas pelo capitalismo entre o trabalho e seus produtos. Segundo, ele argumenta que, como na maioria das vezes o comportamento das pessoas é governado por regras em vez de ser modelado por contingências, o resultado é que elas não têm experiência direta nem com as situações, nem com as consequiências de suas ações. Isso leva a um estranhamento entre as pessoas e seus mundos, conduzindo-as ao consumo de mercadorias e bens culturais, ao contrário de experienciá-los com a produção pessoal. É nesse sentido que ele escreve: "Ouvimos uma peça musical de Smetana, mas não nadamos no Moldau" ( p. 571). Terceiro, e como corolário do anterior: "O Ocidente perdeu sua inclinação para agir" ( p. 572).

Por isso as pessoas dos países mais desenvolvidos "só podem relaxar com a ajuda de sedativos ou tranquiilizantes (...) ou só podem dormir com a ajuda de soníferos (...) elas não somente invejam mas também estão intrigadas com as pessoas dos países menos desenvolvidos, ao percebê-las como alegremente fazendo nada". (p. 573)

Skinner (1986) não defende esse tipo de sociedade como tendo algo a ver com o desenvolvimento ou a emancipação de seres humanos. Pelo contrário, ele comenta que ela não é um modelo para ser imitado por outras sociedades. Isso quer dizer, entre outras coisas, que a abundância das sociedades ricas não é um valor a ser almejado por si mesmo. De acordo com Skinner, existem valores mais básicos e importantes do que esses que podem ser estabelecidos como metas para o desenvolvimento de sociedades alternativas - por exemplo, a prioridade do comportamento modelado por contingências no lugar do comportamento governado por regras, ou o desenvolvimento de relações menos alienadas com o trabalho, as mercadorias e os bens culturais. Pode-se interpretar, como sendo o objetivo de defender valores como esses, que Skinner (1953) argumenta a favor do contracontrole do comportamento, ou da resistência que os seres humanos poderiam desenvolver contra o controle do comportamento que é exercido pelas instituições políticas e sociais (agências de controle em sua parlance) da sociedade capitalista, como as agências governamental, industrial, educacional e terapêutica. Nas palavras de Skinner (1986), isso significa que "um novo conjunto de práticas não pode simplesmente ser imposto por um governo, uma religião, ou um sistema econômico. Caso fosse realizado, esse não seria o conjunto correto de práticas" (p. 573).

Outra linha de evidência sugerindo que Skinner, como Lyotard (1984), vê "sinais que significam o contrário", aponta para as dificuldades que seres humanos têm em compreender culturas diferentes daquelas nas quais foram criados e educados. Isso quer dizer que, segundo Skinner (1990), existem culturas conflitantes e ele detecta um problema exatamente no "fato de que uma cultura prepara um grupo somente para o mundo que se assemelhe àquele em que a cultura evoluiu" (p. 1207) e para ele essa situação "é a fonte de nossa atual preocupação com o futuro de uma terra habitável" (p. 1207). Skinner está se referindo ao sentido antropológico do conceito de cultura, onde se aprende que cada sociedade tem sua própria cultura, que é incomensurável com outra qualquer - embora isso não signifique que a interpretação de outras culturas não seja possível (Geertz, 1973). Assegurada essa possibilidade, ela não é de qualquer modo uma questão trivial, e tanto é assim que, na prática, Skinner (1990) não admite que as pessoas estejam sendo preparadas para compreender culturas conflitantes. Por tudo isso, é perfeitamente plausível concluir que os pensamentos científico, político, social e cultural de Skinner são estranhos às metanarrativas do discurso moderno.

Em suma, o behaviorismo radical não se compromete com as principais teses do discurso moderno, tais como fundacionismo na epistemologia, representacionismo na filosofia da linguagem e metanarrativas científicas, políticas, sociais e culturais concernentes ao progresso do Ocidente. Portanto, o behaviorismo radical configura-se como divergência decisiva em relação ao discurso moderno.

\section{Conclusão}

É, então, o behaviorismo radical uma posição pós-moderna? O behaviorismo radical configura-se como um estilo de pensamento em direção ao discurso pós-moderno, por- 
que, primeiro, incorpora um conceito de linguagem e significado com notáveis semelhanças com os conceitos de linguagem e significado como uso elaborados por Wittgenstein (Abib, 1994b; Day, 1969; Waller, 1977); e, como já foi visto, o discurso pós-moderno defende essa filosofia da linguagem de Wittgenstein (Lyotard, 1984; Murphy, 1990; Rorty, 1980, 1990).

Segundo, a epistemologia interativa-pragmática de Skinner (Burton, 1980; Skinner, 1956/1972,1957,1974;Zuriff, 1985) está muito próxima do behaviorismo epistemológico de Rorty (1980) no sentido de que a justificação do conhecimento é uma questão de prática social. Ou seja, se de acordo com Rorty, o que substitui o fundacionismo epistemológico "é a sociologia e a história da ciência" (p. 226), a epistemologia interativapragmática de Skinner, com as condições que têm de investigar a psicologia do cientista (Zuriff), poderia compartilhar com a sociologia e história da ciência a tarefa de investigar a natureza da ciência.

Rorty (1980) não concordaria com essa sugestão. Por exemplo, ele completa sua sentença anterior assim: "E não é certamente a psicologia" (p. 226). Não é claro, porém, como essa interdição de Rorty às possibilidades epistemológicas da psicologia seria aplicável ao behaviorismo radical, porque ele se engana com respeito ao pensamento de Skinner, identificando-o com o behaviorismo metodológico. Por exemplo, referindo-se a Skinner, ele escreve: "Behaviorismo metodológico de Skinner" (Rorty, p. 213). Mas, Skinner não defende o behaviorismo metodológico, seja no sentido mais amplo, que aposta no método científico como a marca registrada da ciência (Mackenzie, 1977; Skinner, 1956/1972), seja no sentido mais específico, que nega a possibilidade da ciência do comportamento investigar eventos privados (Skinner, 1945, 1974).

Terceiro, se o behaviorismo radical é capaz de participar de uma "conversação holística" sobre a natureza da ciência, ou de investigar a justificação do conhecimento como uma questão de prática social, ele pode compartilhar com o behaviorismo epistemológico as concepções de que epistemologia e hermenêutica referem-se, respectivamente, a discursos "normais" e "anormais", onde a ênfase do behaviorismo radical poderia ser localizada nas dimensões psicológicas apresentadas por todos os discursos, sejam eles "normais" ou "anormais".

Nesse sentido, o texto de Lamal (1983) é muito mais perceptivo às similaridades existentes nos pensamentos de Rorty e Skinner (por exemplo, a perspectiva pragmática que compartilham) do que o texto de Woolfolk (1983). Woolfolk comenta que "é difícil imaginar como um movimento do fundacionismo epistemológico em direção à hermenêutica poderia resultar em uma justificação adicional para o behaviorismo" (p. 112). No entanto, hermenêutica representa uma longa tradição de pensamento metodológico e filosófico no Ocidente, e é uma palavra carregada de sentido (Palmer, 1969/1986). Rorty (1980) argumenta que seu uso de hermenêutica não significa nem o nome de uma disciplina, nem um método de investigação, significando apenas uma atitude que é muito próxima do pragmatismo filosófico.
O behaviorismo radical não representa a tendência do Sistema (Establishment) psicológico norte-americano (Day, 1983; Guttman, 1977; Smith, 1983). E Skinner tinha consciência dessa situação. Suas últimas inquietações, escritas na noite anterior à sua morte e postumamente publicadas, foram: "É uma questão a ser decidida no futuro se a análise do comportamento será chamada de psicologia" (1990, p. 210). Não se verifica aí uma profunda dúvida hermenêutica no sentido de Rorty? E não pertence ela a uma autêntica mente pós-moderna?

A atualidade do discurso pós-moderno, já em curso nas últimas décadas da produção intelectual do grande psicólogo norte-americano, talvez possa se constituir naquele futuro a que ele se referia, seja para ajudar a esclarecer a originalidade de um pensamento difícil de ser compreendido com base nos pressupostos e temas do discurso moderno, seja para, com essa elucidação, contribuir para a reflexão sobre o behaviorismo radical como um tipo de epistemologia do presente, com notáveis condições de defender a análise do comportamento não somente como psicologia, mas sobretudo e especialmente, como uma psicologia com possibilidades de sugerir diretrizes para projetos pós-modernos de psicologia.

Finaliza-se esse texto com o pressentimento de que se o discurso pós-moderno vingar, Skinner provavelmente será melhor compreendido no próximo século.

\section{Referências}

Abib, J. A. D. (1994a). O contextualismo do comportamento verbal: a teoria skinneriana do significado e sua crítica ao conceito de referência. Psicologia: Teoria e Pesquisa, 10, 473-487.

Abib, J.A.D. (1994b). A atualidade do livro Verbal Behavior de B.F. Skinner: um comentário. Psicologia: Teoria e Pesquisa, 10, 467-472.

Abib, J.A.D. (1997). Teorias do comportamento e subjetividade na psicologia. São Carlos: Editora da Universidade Federal de São Carlos.

Austin, J.L. (1975). How to do things with words. Oxford: Oxford University Press. (Originalmente publicado em 1962)

Ayer, A.J. (1971). Lenguaje, verdad y lógica. (M. Suárez, Trad.) Barcelona: Edicioncs Martinez Roca. (Trabalho original publicado em 1936)

Ayer, A.J. (1965). Introducción del compilador. Em A.J. Ayer (Org.), El positivismo lógico (pp. 9-34). (L. Aldama, U. Frisch, C.N. Molina, F.M. Torner \& R.R. Harrel, Trads.) México: Fondo de Cultura Econômica. (Trabalho original publicado em 1959)

Baldwin, J.D. (1988). Mead and Skinner; Agency and determinism. Behaviorism, 16, 109-127.

Bernstein, R.J. (1989). Beyond objectivism and relativism. Oxford: Basil Blackwell.

Burton, M. (1980). Determinism, relativism and the behavior of scientists. Behaviorism, 8, 113-122.

Chaiklin, S. (1992). From theory to practice and back again: What does post-modern philosophy contribute to psychological science? Em S. Kvale (Org.), Psychology and post-modernism (pp. 194-208). London: Sage Publications. 
Day, W. (1969). On certain similarities between the Philosophical Investigations of Ludwig Wittgenstein and the operationalism of B.F. Skinner. Journal of the Experimental Analysis of Behavior, 12, 489-506.

Day, W. (1983). On the difference between radical and methodological behaviorism. Behaviorism, 11, 89-102.

Garret, R. (1979). Value conflict in a skinnerian analysis. Behaviorism, 7, 9-16.

Geertz, C. (1973). The interpretation of culture. New York: Basic Books.

Gergen, K.J. (1992). Toward a post-modern psychology. Em S. Kvale (Org.), Psychology and post-modernism (pp. 17-30). London: Sage publications.

Graham, N. (1977). On what is good: A study of B.F. Skinner's operant behaviorist view. Behaviorism, 5, 97-112.

Guttman, N. (1977). On Skinner and Hull. American Psychologist, 32, 321-328

Habermas, J. (1981). Modernity versus post-modernity. (S. BenHabib, Trad.) New German Critique, 22, 3-14.

Hanfling, O. (1989). Wittgenstein's later philosophy. London: The Macmillan Press.

Hoccut, M. (1985). The truth in behaviorism: A review of G.E. Zuriff: Behaviorism: A conceptual reconstruction. Behaviorism, 13, 77-82.

James, W. (1976). Essays in radical empiricism. Cambridge: Harvard University Press. (Originalmente publicado em 1912)

James, W. (1988). Pragmatism. Indiana: Hackett Publishing Company, Inc. (Originalmente publicado em 1907)

Jameson, F. (1984). Post-modernism, or the cultural logic of late capitalism. New Left Review, 146, 53-92.

Johnson, R.J. (1963). Discussion: A commentary on "radical behaviorism". Philosophy of Science, 30, 274-285.

Kvale, S. \& Grenness, C.E. (1967). Skinner and Sartre: Towards a radical phenomenology of behavior? Review of Existencial Psychology and Psychiatry, 7, 128-150.

Kvale, S. (1992). Post-modern psychology: A contradiction in terms? Em S. Kvale (Org.), Psychology and post-modernism (pp. 31-57). London: Sage Publications.

Kolakowski, L. (1976). La philosophic positiviste. (C. Brendel, Trad.) Paris: Editions Denõel/Gonthier. (Trabalho original publicado em 1966)

Kuhn, T. (1962). The structure of scientific revolutions. Chicago: University of Chicago Press.

Lacey, H. \& Schwartz, B. (1986). Behaviorism, intentionality, and socio-historical structure. Behaviorism, 14, 193-210.

Lamal, P. A. (1983). A cogent critique of epistemology leaves radical behaviorism unscathed. Behaviorism, 11, 103-109.

Lather, P. (1992). Post-modernism and the human sciences. Em S. Kvale (Org.), Psychology and post-modernism (pp. 88-109). London: Sage Publications.

Lyons, J. (1980). Semântica - 1. (W. Ramos, Trad.) Lisboa: Editorial Presença/Martins Fontes. (Trabalho original publicado em 1977)

Lyotard, J.F. (1984). The post-modern condition: A report on knowledge. Minneapolis: University of Minnesota Press.

Lyotard, J.F (1989). Defining the post-modern (G. Bennington, Trad.), Em L. Appignanesi (Org.), Post-modernism: 1CA docu- ments (pp. 6-7). London: Free Association Books. (Trabalho original publicado em 1986)

Mackenzie, B.D. (1977). Behaviorism and the limits of scientific method. London: Routledge and Kegan Paul.

Madsen, P. (1992). 'Post-modernism' and 'late capitalism': On terms and reality. Em S. Kvale (Org.), Psychology and post-modernism (pp. 209-223). London: Sage Publications.

Michael, M (1992). Post-modern subjects: Toward a transgressive social psychology. Em S. Kvale (Org.), Psychology and postmodernism (pp. 74-87). London: Sage Publications.

Murphy, J. (1993). O pragmatismo: de Pierce a Davidson. (J. Costa, Trad.). Porto: Edições ASA. (Trabalho original publicado em 1990)

Murphy, N. (1990). Scientific realism and post-modern philosophy. British Journal Philosophy of Science, 41, 291-303.

Palmer, R.E. (1986). Hermenêutica. (M.L.R. Ferreira, Trad.) Lisboa: Edições 70. (Trabalho original publicado em 1969)

Polkinghome, D.E. (1989). Chaging conversations about human science. Em S. Kvale (Org.), Issues of validity in qualitative research (pp. 13-45). Sweden: Studentlitteratur.

Polkinghome, D.E. (1992). Post-modern epistemology of practice. Em S. Kvale (Org.), Psychology and post-modernism (pp. 146165). London: Sage Publications.

Richer, P. (1992). An introduction to deconstructionist psychology. Em S. Kvale (Org.), Psychology and post-modernism (pp. 110-118). London: Sage Publications.

Rorty, R. (1980). Philosophy and the mirror of nature. New Jersey: Princenton University Press.

Rorty, R. (1982). Consequences of pragmatism. Minneapolis: University of Minnesota Press.

Rorty, R. (1985). Habermas and Lyotard on post-modernity. Em R.J. Bernstein (Org.), Habermas and modernity (pp. 161-175). Oxford: Basil Blackwell.

Rorty, R. (1990). Contingency, irony, and solidarity. Cambridge: Cambridge University Press.

Rorty, R. (1993). Introdução: O pragmatismo como antirepresentacionismo (J. Costa, Trad.). Em Murphy J. (Org.), $O$ pragmatismo: de Peirce a Davidson (pp. 7-13). Porto: Edições Asa. (Trabalho original publicado em 1990)

Rottschaefer, W.A. (1980). Skinner's science of value. Behaviorism, 8, 99-112.

Ryle, G. (1980). The concept of mind. Middlesex: Penguin Books. (Originalmente publicado em 1949)

Searle, J. (1989). Speech acts. Cambridge: Cambridge University Press. (Originalmente publicado em 1969)

Shotter, J. (1992). 'Getting in touch': the meta-methodology of a post-modem science of mental life. Em S. Kvale (Org.). Psychology and post-modernism (pp. 58-73). London: Sage Publications.

Skinner, B.F. (1945). The operational analysis of psychological terms. Psychological Review, 52, 270-277.

Skinner, B.F. (1950). Are theories of learning necessary? Psychological Review, 57, 93-216.

Skinner, B.F. (1953). Science and human behavior. New York: The Macmillan Company.

Skinner, B.F. (1957). Verbal behavior. New York: Appleton-Century-Crofts. 
Skinner, B.F. (1968). The techonology of teaching. New York: Appleton-Century-Crofts.

Skinner, B.F. (1969). Contingencies of reinforcement. New York: Appleton-Century-Crofts.

Skinner, B.F. (1971). Beyondfreedom \& dignity. New York: Alfred, A. Knopf.

Skinner, B.F. (1972). A case history in scientific method. Em Skinner, B.F. (Org.), Cumulative record (pp. 101-124). New York: Appleton-Century-Crofts. (Originalmente publicado em 1956)

Skinner, B.F. (1974). About behaviorism. New York: Alfred, A. Knopf.

Skinner, B.F. (1977). Why I am not a cognitive psychologist. Behaviorism, 5, 1-10.

Skinner, B.F. (1986). What is wrong with daily life in the Western world? American Psychologist, 41, 568-574.

Skinner, B. F. (1989). The behavior of the listener. Em S. C. Hayes (Org.), Rule-governed behavior (pp. 85-96). New York: Pleem um Press.

Skinner, B .F. (1990). Can psychology be a science of mind? American Psychologist, 45, 1206-1210.

Smith, T.L. (1983). Skinner's environmentalism: The analogy with natural selection. Behaviorism, 11, 133-153.

Stevenson, C.L. (1965). El significado emotivo de los términos éticos (L. Aldama, U. Frisch, C.N. Molina, FM. Torner \& R.R.
Harrel, Trads.). Em A.J. Ayer (Org.), El positivismo lógico (pp. 269-286). México: Fondo de Cultura Econômica. (Trabalho original publicado em 1959)

Urmson, J.O. (1972). Ideas. Em P. Edwards (Org.), The encyclopedia of philosophy (Volume 4, pp. 118-121). London: Collier Macmillan Publishers.

Waller, B. (1977). Chomsky, Wittgenstein, and the behaviorist perspective on language. Behaviorism, 5, 43-59.

Waller, B. (1982). Skinner's two stages value theory. Behaviorism, $10,25-44$.

Wiley,N. (1996). O self semiótico. (E.P Rouanet, Trad.) São Paulo: Edições Loyola. (Trabalho original publicado em 1994)

Wittgenstein, L. (1988). Philosophical investigations. Oxford: Basil Blackwell. (Trabalho original publicado em 1953)

Wittgenstein, L. (1989). The blue and brown books. Oxford: Basil Balckwell. (Trabalho original publicado em 1958)

Woolfolk, R. (1983). Behaviorism, Rorty, and the end of epistemology. Behaviorism, 11, 11-113.

Young, N. (1992). Post-modern self-psychology mirrored in science and the arts. Em S. Kvale (Org.), Psychology and postmodernism (pp. 135-145). London: Sage Publications.

Zuriff, G. (1985). Behaviorism: A conceptual reconstruction. New York: Columbia University Press. 